\title{
Endovascular treatment with flow diverters of recanalized and multitreated aneurysms initially treated by endovascular approach
}

\author{
Azzedine Benaissa, ${ }^{1}$ Anne-Christine Januel, ${ }^{2}$ Denis Herbreteau, ${ }^{3}$ Jérôme Berge, ${ }^{4}$ \\ Mohamed Aggour, ${ }^{5}$ Krzysztof Kadziolka, $^{1}$ Christophe Cognard, ${ }^{2}$ Laurent Pierot ${ }^{1}$
}

\begin{abstract}
${ }^{1}$ Department of Neuroradiology, Centres Hospitaliers Universitaires de Reims, Reims, France

2Department of Neuroradiology, Centres Hospitaliers Universitaires de Toulouse, Toulouse, France ${ }^{3}$ Department of Neuroradiology, Centres Hospitaliers Universitaires de Tours, Tours, France ${ }^{4}$ Department of Neuroradiology, Centres Hospitaliers Universitaires de Bordeaux, Bordeaux, France ${ }^{5}$ Department of Neuroradiology, Centres Hospitaliers Universitaires de Saint-Etienne, Saint-Etienne, France
\end{abstract}

\section{Correspondence to} Professor Laurent Pierot, Service de neuroradiologie, Hopital Maison Blanche 45, rue Cognacq Jay, Reims cedex 51092, France;

Ipierot@gmail.com

Received 5 December 2013 Revised 3 January 2014 Accepted 3 January 2014 Published Online First 21 January 2014

\section{CrossMark}

\section{To cite: Benaissa $A$}

Januel A-C, Herbreteau D,

et al. J Neurolntervent Surg

2015;7:44-49.

\section{ABSTRACT}

Purpose To evaluate the feasibility, safety and efficacy of endovascular treatment with flow diverters in patients with recanalized and multitreated aneurysms in a retrospective, multicenter, single-arm study.

Methods The study included 29 patients with 29 recanalized aneurysms who were treated by flow diverters (Silk or Pipeline devices). Pre- and postprocedural complications and morbidity and mortality rates were evaluated and functional outcomes (modified Rankin Score (mRS)) at 1 month (short-term) and 34 months (mid-term) were compared with preoperative mRS (before the procedure). Mid-term angiographic follow-up was performed assessing aneurysmal occlusion by the Montreal scale (complete occlusion, neck remnant, aneurysm remnant).

Results Placement of the flow diverters was achieved in all patients. Two misdeployments of the flow diverters necessitated balloon dilation in two patients, which was associated with stent delivery in one patient. Permanent morbidity related to treatment was $6.9 \%(2 / 29)$,

transient morbidity was $10.3 \%(3 / 29)$ and there were no deaths resulting from the treatment. One patient died from a myocardial infarct 4 weeks after the procedure. $25 / 29$ patients $(86.2 \%)$ had a good final functional outcome, 26/29 (89.7\%) had an unchanged functional outcome and 2/29 patients (6.9\%) had clinical worsening. Angiographic follow-up showed complete occlusion in $17 / 28$ patients $(60.7 \%)$, neck remnants in $6 / 28$ patients $(21.4 \%)$ and residual aneurysms in $5 / 28$ (17.9\%).

Conclusions Flow diverter placement is feasible and safe in patients with recanalized and multitreated aneurysms. The procedure is associated with a high percentage of good functional outcomes as well as good mid-term anatomical results $(82.1 \%)$.

\section{INTRODUCTION}

Endovascular treatment with coils has become the first-line treatment for intracranial aneurysms (IA) with satisfactory clinical and anatomical results. ${ }^{1}{ }^{2}$ Although endovascular coiling is a less invasive procedure than clipping, reopening occurs in 20.8\%, necessitating retreatment in $10 \%$ of cases. ${ }^{3}$ The potential reasons for aneurysm recurrence or recanalization include coil compaction, aneurysm regrowth and coil migration through the aneurysm wall. ${ }^{4}$ The clinical consequence of aneurysm remnants is not clear, but it has been shown that the risk of aneurysmal rebleeding is strongly correlated with the degree of aneurysmal occlusion after coiling. ${ }^{5}$ Several approaches have been proposed to reduce the recanalization rate (eg, modified coils, balloon-assisted coiling, stent-assisted coiling), but their efficacy in preventing aneurysm recanalization has not been clearly demonstrated. ${ }^{6-8}$ Indications and modalities of treating aneurysm remnants are not clearly defined and vary considerably in practice. Recanalized aneurysms can be treated by a repeat endovascular approach or clipping. ${ }^{4-11}$ Since 2007, intracranial flow diverters (FDs) have emerged as a promising technique for the treatment of large, giant or dissecting aneurysms by hemodynamic (modification of intra-aneurysmal flow leading to aneurysm thrombosis) and biologic means (neointimal growth). ${ }^{12-18}$ To our knowledge, only a few small studies have evaluated the treatment of aneurysm remnants with FDs. ${ }^{19}$ The aim of this study is to report a retrospective multicenter series evaluating the treatment of recanalized and multitreated aneurysms by FDs with regard to feasibility, safety and anatomical results.

\section{METHODS}

Population

This retrospective study was performed after approval of the local Institutional Review Board. According to the study design, informed consent was waived.

From 2010 to 2012, 29 patients with 29 aneurysm remnants detected during follow-up were treated in five participating hospitals and included in the present series. The study group consisted of 12 men and 17 women ranging in age from 25 to 72 years (mean $51.7 \pm 12$ years, median 54 years). Therapeutic approaches were discussed between the neurosurgical and neurointerventional teams in a multidisciplinary decision-making process. Retreatment was usually agreed for any aneurysm remnant or remnant growth. Twenty-four patients had previously ruptured IA and four had unruptured IA. One patient initially presented with compressive symptoms (oculomotor palsy) and had aneurysm rupture during digital subtraction angiography (DSA).

Twenty-one patients $(72.4 \%)$ were treated once before retreatment by flow diversion (recanalized IA) and eight patients (27.6\%) were treated twice (multitreated IA). Nineteen of the 21 recanalized IA were treated with coils and two with coils and stenting. All of the eight multitreated IA were 
initially treated with coils, four were retreated with coils alone, three with coils plus stenting and one by stenting alone. Before FD treatment, six of the 29 patients $(20.7 \%)$ had already been treated with stents. The mean time between the last treatment and FD utilization was $28.1 \pm 40.9$ months (range 1180 months, median 14 months).

Nine aneurysms $(31.0 \%)$ were fusiform or dissecting and 20 $(69.0 \%)$ were saccular. Fourteen aneurysms (48.3\%) were small $(<10 \mathrm{~mm})$ and $15(51.7 \%)$ were large or giant $(>10 \mathrm{~mm})$. Among the saccular aneurysms the aneurysm size ranged from 2 to $35 \mathrm{~mm}$ (mean $10.4 \pm 5.92 \mathrm{~mm}$, median $9.4 \mathrm{~mm}$ ), with neck $<4 \mathrm{~mm}$ in seven aneurysms and $\geq 4 \mathrm{~mm}$ in 13 aneurysms. Twenty-one aneurysms were located in the internal carotid artery (ICA), two in the anterior communicating artery (Acom), one in the middle cerebral artery (MCA) and five in the posterior circulation. The characteristics of the patients and aneurysms are summarized in table 1 .

In the eight multitreated patients, four aneurysms were located in the anterior circulation and four in the posterior circulation; six were saccular and two were fusiform/dissecting.

Before the procedure, 27 of the 29 subjects $(93.1 \%)$ had a modified Rankin Scale (mRS) score of 0-2 and two (6.9\%) had an initial mRS score of 4 as a consequence of initial subarachnoid hemorrhage.

\section{Flow diverters}

Two FDs, Pipeline and Silk, were used. The Pipeline device (eV3/Covidien, Irvine, California, USA) is a woven wire mesh tube made of platinum (25\%) and cobalt-nickel alloy (75\%) and the

Silk device (SFD, Balt Extrusion, Montmorency, France) is a braided mesh cylinder composed of 48 nickel-titanium (nitinol) strands.

\section{Endovascular procedure}

Antiplatelet therapy (clopidogrel) was used for all subjects in a dose of $75 \mathrm{mg} /$ day 3-7 days before the procedure. After the procedure the patients were given clopidogrel in the same dose along with $160 \mathrm{mg}$ aspirin for 2-3 months. Aspirin was

\begin{tabular}{|c|c|}
\hline \multicolumn{2}{|l|}{ Gender } \\
\hline Female/male & $17 / 12$ \\
\hline \multicolumn{2}{|l|}{ Aneurysm size } \\
\hline$<10 \mathrm{~mm}$ & $14 / 29(48.3 \%)$ \\
\hline$>10 \mathrm{~mm}$ & $15 / 29(51.7 \%)$ \\
\hline \multicolumn{2}{|l|}{ Aneurysm morphology } \\
\hline Saccular/fusiform-dissecting & $20 / 29(69 \%) / 9 / 29(31 \%)$ \\
\hline \multicolumn{2}{|l|}{ Aneurysm location } \\
\hline ICA & $21 / 29(72.4 \%)$ \\
\hline ACA/AcomA & $2 / 29(6.9 \%)$ \\
\hline MCA & $1 / 29(3.4 \%)$ \\
\hline Posterior & $5 / 29(17.2 \%)$ \\
\hline \multicolumn{2}{|l|}{ Previous treatment } \\
\hline Coils+stent & $6 / 29(20.7 \%)$ \\
\hline Coils & $23 / 29(79.3 \%)$ \\
\hline \multicolumn{2}{|l|}{ Number of previous treatments } \\
\hline 1 & $21 / 29(72.4 \%)$ \\
\hline$>1$ & $8 / 29(27.6 \%)$ \\
\hline
\end{tabular}

maintained for at least 1 year. Evaluation of systemic antiplatelet resistance was not performed.

All patients were treated by senior interventional neuroradiologists with at least 5 years' experience. In all patients the procedure was performed under general anesthesia with periprocedural administration of heparin.

Anteroposterior and lateral views and three-dimensional acquisition were recorded to choose the working projection. Unilateral femoral access was obtained and a 6 Fr catheter was inserted into the parent vessel.

\section{Periprocedural and delayed complications}

Procedural, acute, subacute and delayed complications were assessed during the procedure, within $24 \mathrm{~h}$ after the procedure, within a month following the procedure and more than 1 month after the procedure, respectively. Ischemic and hemorrhagic events as well as other complications were listed.

\section{Short-term and mid-term clinical follow-up}

Clinical outcome was graded at 1 month (short-term) by a senior neuroradiologist according to mRS. Short-term mRS was compared with the clinical status before the procedure. Permanent morbidity related to treatment was defined as any increase in $\mathrm{mRS}$ due to the procedure in patients with initial $\mathrm{mRS}>2$, or $\mathrm{mRS}>2$ in patients with initial $\mathrm{mRS}=0,1$ or 2. Transient morbidity related to treatment was defined as any transient worsening of the clinical status. Mid-term mRS was also evaluated at 3 months.

\section{Imaging follow-up}

Mid-term angiographic follow-up was evaluated by the Montreal scale, classifying the degree of aneurysmal occlusion into three groups: complete occlusion (Grade A), residual neck (Grade B) and residual aneurysm (Grade C). Classes 1 and 2 were grouped together as an adequate occlusion group.

Perianeurysmal edema at 3 months was also evaluated on FLAIR sequences for each patient.

\section{RESULTS \\ FD deployment}

Among the 29 patients with recanalized aneurysms treated by flow diversion, seven were retreated with the Silk device and 22 with the Pipeline device. FD placement was achieved in all patients with 31 FDs delivered. Two patients were treated with two partially overlapping FDs (Pipeline). In the six patients previously treated with a stent, the FD device was easily placed and deployed within the stent.

Twenty-seven $(87.1 \%)$ of the 31 FDs placed were correctly deployed, two $(6.5 \%)$ were underdeployed and two $(6.5 \%)$ did not completely cover the aneurysm neck. FDs alone were placed in 28 patients. Coils were added in one of the two patients with insufficient coverage of the neck by the FD (patient 18) while, in another patient (patient 23), the FD moved back during the deployment and no coils were added. In the two patients in whom the FD was underdeployed, balloon dilation was required in one patient (patient 13) and placement of a Neuroform stent (Stryker Neurovascular, Kalamazoo, Michigan, USA) to expand the intra-FD stenosis was performed in the other (patient 27).

\section{Periprocedural and delayed complications \\ Periprocedural complications}

Acute and subacute complications were observed in five of the 29 patients $(17.2 \%)$ (table 2): two (6.9\%) thromboembolic events, one (3.4\%) hemodynamic complication and two $(6.9 \%)$ 
Table 2 Per- and post-procedural complications, mid-term anatomic results and clinical outcome for each patient

\begin{tabular}{lc}
\hline FD underdeployment/insufficient coverage of the neck & $4 / 29(13.8 \%)$ \\
Per procedural complications & None \\
Acute/subacute complications & $5 / 29(17.2 \%)$ \\
Initial mRS & $27 / 29(93.1 \%)$ \\
$\leq 2$ & $2 / 29(6.9 \%)$ \\
$>2$ & \\
1 month mRS & $24 / 29(82.8 \%)$ \\
$\leq 2$ & $5 / 29(17.2 \%)$ \\
$>2$ & \\
3 months mRS & $25 / 29(86.2 \%)$ \\
$\leq 2$ & $4 / 29(13.8 \%)$ \\
$>2$ & \\
Montreal scale & $17 / 27(60.7 \%)$ \\
Grade A & $6 / 27(21.4 \%)$ \\
Grade B & $5 / 27(17.9 \%)$ \\
Grade C & \\
\hline FD, flow diverter; mRS, modified Rankin Score.
\end{tabular}

hemorrhagic complications. No periprocedural complication occurred in the six patients previously treated with stents.

\section{Thromboembolic complications}

In one patient with a ruptured MCA aneurysm treated once with coils 13 months earlier (patient 10), an MCA occlusion occurred a few hours after the procedure leading to an acute stroke with right hemiplegia ( $\mathrm{mRS}$ at 1 month $=5)$. Postoperative evaluation of systemic antiplatelet resistance showed that the patient was resistant to antiaggregant medication. In another patient a ruptured dissecting fusiform vertebral (V4 segment, posterior inferior cerebellar artery (PICA)) aneurysm (patient 8) was initially treated twice with coils at 60 and 53 months before FD placement. The procedure was uneventful but the patient presented with Wallenberg syndrome 1 day after the procedure (mRS at 1 month=2). MRI performed immediately after the procedure showed a small ischemic lesion in the medulla. The TOF sequence showed the PICA to be patent. This ischemic complication was probably due to an occlusion of perforating arteries. Three months after the treatment neurological improvement was observed $(\mathrm{mRS}=1)$.

\section{Hemodynamic complications}

A patient with a ruptured vertebral aneurysm treated once by coiling 18 months earlier (patient 21) presented with a transient cerebral ischemia immediately after the procedure. MRI showed no diffusion abnormality. The neurologic deficit (hemiplegia) spontaneously resolved after a few hours $(m R S=0)$ and was probably due to a hemodynamic mechanism.

\section{Hemorrhagic complications}

Two hemorrhagic strokes occurred remotely from the treated aneurysm and were ipsilateral. In one case a patient with a right ICA aneurysm was treated 33 months before the flow diversion procedure by coils (patient 19) and retreated 22 months after by a combination of coils and a Neuroform stent. After treatment with the Pipeline device the patient experienced an acute intracranial hemorrhage with a right intracerebral hemorrhage in the frontal lobe. He underwent neurosurgical treatment with

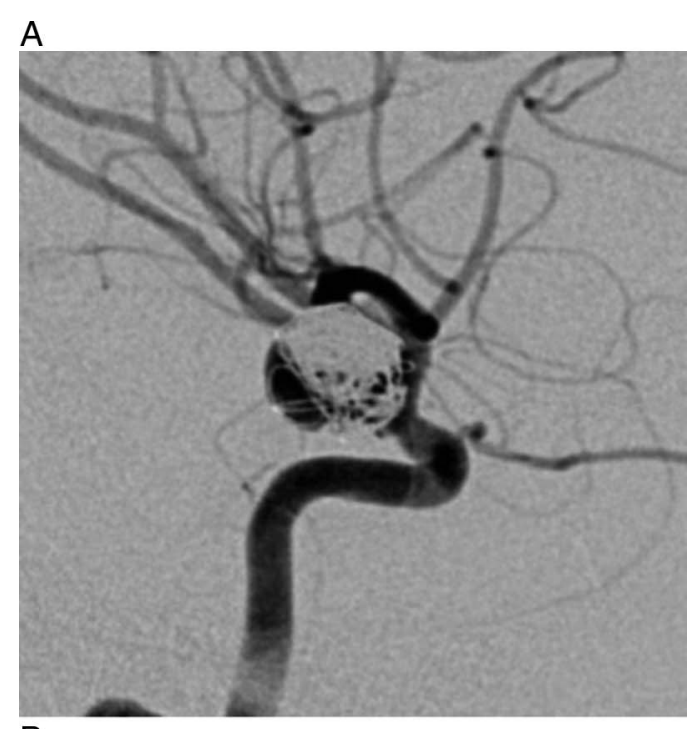

B

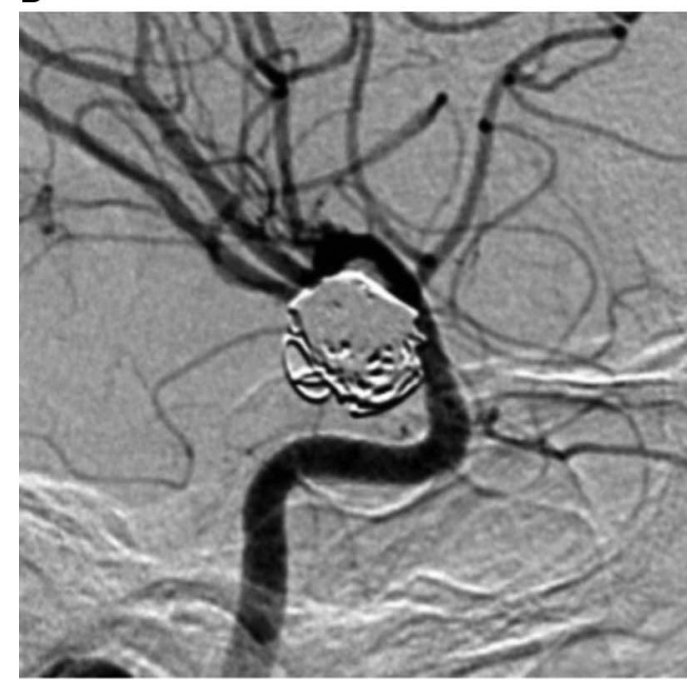

C

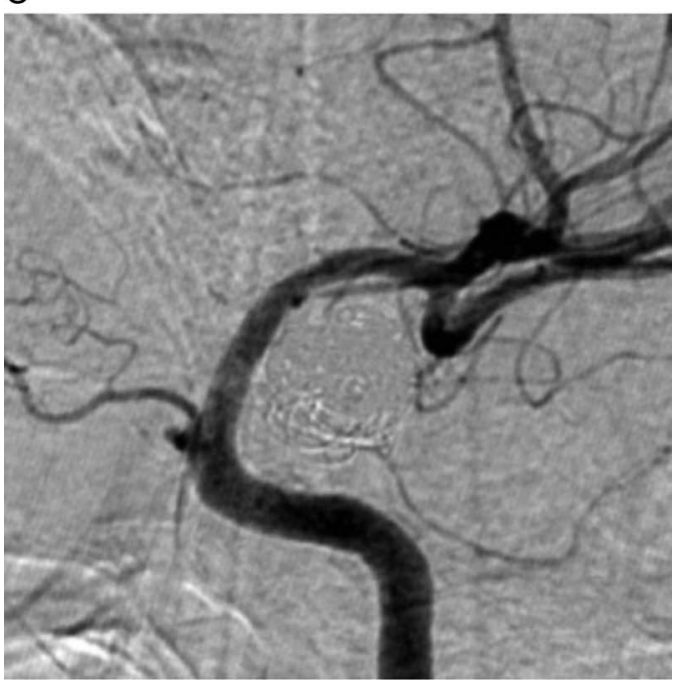

Figure 1 Left internal carotid artery (ICA) residual aneurysm in a middle-aged patient. (A) Conventional angiography shows a left ICA coiled aneurysm with residual opacification (grade C). Angiographic control 12 months after the flow diverting procedure shows (B) complete aneurysm occlusion (grade A) with (C) no parent artery stenosis. 


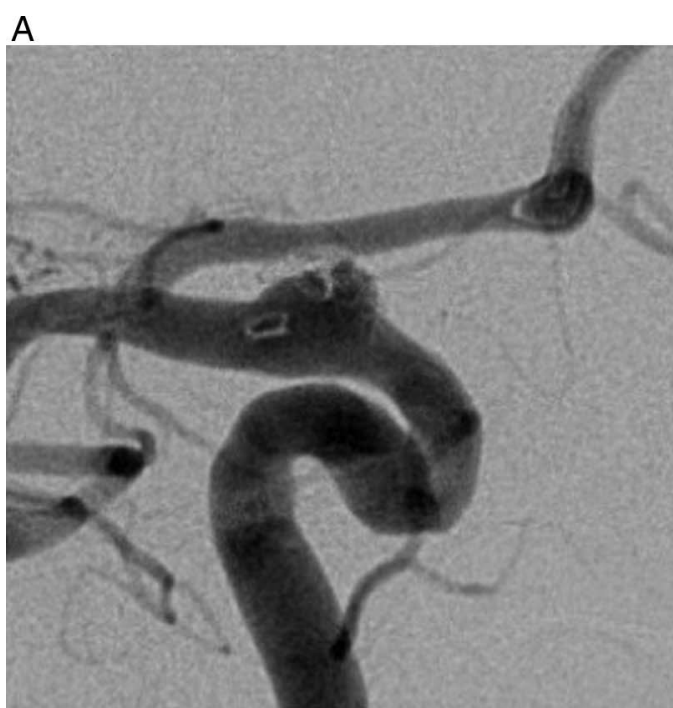

B

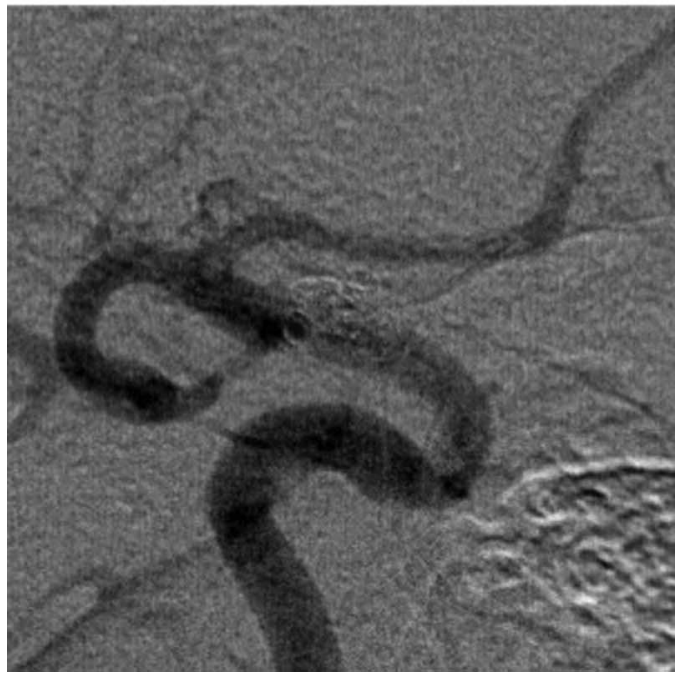

Figure 2 Right internal carotid artery (ICA) residual aneurysm previously treated with coils+stent in a middle-aged patient.

(A) Conventional angiography shows a right ICA aneurysm treated with coils and stent (grade C). (B) Angiographic control 12 months after the flow diverting procedure shows complete aneurysm occlusion with no parent stenosis.

a craniotomy and, at discharge, had left hemiparesis (mRS at 1 month=4). Three months later, the patient retained a slight spasticity of the left hand $(\mathrm{mRS}=1)$.

Another patient with a left ruptured ICA aneurysm was treated twice by coils (patient 20). A left frontal hemorrhagic stroke occurred 3 days after the flow diversion procedure causing a temporary aphasia (mRS at 1 month $=2)$. Three months after the procedure the patient had no sequelae $(\mathrm{mRS}=0)$.

\section{Delayed complications}

No delayed rupture, delayed thrombosis of the parent artery, delayed hemorrhagic complications or death related to the procedure occurred.

One patient died of a myocardial infarct 4 weeks after the procedure. In this case the procedure was performed without complication and the patient was discharged home in his baseline status before the occurrence of the myocardial infarct. Consequently, this event was not considered as a procedurerelated complication.

\section{Clinical and angiographic follow-up}

Short-term clinical follow-up

At 1 month 24 of the 29 patients $(82.8 \%)$ had a good functional outcome (mRS score $0-2$ ) and five (17.2\%) had a mRS score of $>2$. There were no deaths related to the treatment. One patient died 4 weeks after the treatment of myocardial infarction which was unrelated to the treatment. Permanent morbidity related to the treatment was observed in two patients $(6.9 \%$ ) (one of seven patients treated with the Silk FD and one of 22 patients treated with the Pipeline FD), and transient morbidity was observed in three patients $(10.3 \%)$ (all of whom were treated with the Pipeline FD). Twenty-six of the 29 patients $(89.7 \%)$ had unchanged or improved clinical status, two (6.9\%) had a worsened clinical status and one patient (3.4\%) died.

Among the five patients with $\mathrm{mRS}>2$, one (patient 10) had $\mathrm{mRS}=5$ because of a thromboembolic complication (MCA occlusion, preoperative $\mathrm{mRS}=0$ ), one (patient 19) had $\mathrm{mRS}=4$ because of an hemorrhagic complication (remote hematoma, initial $\mathrm{mRS}=0$ ), two patients had unchanged $\mathrm{mRS}=4$ as a result of a previous aneurysm rupture and one patient died from a myocardial infarction (see above).

At 3 months, among the four living patients with short-term mRS $>2$, one (patient 19) had a good functional outcome with complete recovery of his hemiplegia (remote hematoma, mRS at 1 month=4) and three had permanent clinical worsening (thromboembolic complication in one patient and previous subarachnoid hemorrhage in two); 25 of the 29 patients $(86.2 \%)$ had a final good functional outcome.

\section{Mid-term imaging follow-up}

All patients had MRI with MR angiography and 27 patients had DSA (one patient refused DSA). The latest DSA control for the patients was obtained at a mean of $6.1 \pm 4.9$ months (median 5 months, range 3-21 months). DSA controls showed adequate occlusion in 23 of 28 patients (82.1\%) with 17 complete occlusions (60.7\%), six neck remnants (21.4\%) and five residual aneurysms $(17.9 \%)$ (figures 1,2$)$. No parent artery stenosis was visualized in any of the subjects. Occlusion of the parent vessel was seen in one patient (clinical worsening, patient 10).

Seven of the eight multitreated patients had mid-term angiographic follow-up (one patient died from a myocardial infarction); six $(85.7 \%)$ had adequate occlusions (five complete occlusions and one neck remnant) and, in one patient (14.3\%), aneurysmal remnant was observed. No perianeurysmal edema was observed on MRI in the 28 patients at 3 months.

\section{DISCUSSION}

This study shows that the use of flow diversion devices is feasible and useful for the endovascular treatment of aneurysm remnants in selected cases. However, this treatment is associated with a relatively high rate of complications compared with the standard reference treatment, necessitating precise evaluation of the indications for the use of these devices.

Among the studied population, all aneurysms belonged to a relatively high-risk group for recanalization as they were previously ruptured $(n=24)$ and/or large or giant $(n=15)$ and/or with a large neck $(n=22)$. These findings are in concordance with the literature concerning risk factors for the retreatment of an aneurysm. Ries et $a l^{11}$ showed that neck widths $>4 \mathrm{~mm}$, diameter $>10 \mathrm{~mm}$, the presence of a residual aneurysm after initial treatment and rupture were the principal predictors of aneurysmal recurrence. The clinical significance of remnants is not clearly established; not all remnants need to be treated because the potential risk of bleeding is uncertain and differs 
from one case to another, but it is admitted that remnants with a high risk of bleeding (such as aneurysm remnants or evolutive remnants) have to be treated in order to reduce the further risk of rupture.

The feasibility of the treatment was satisfactory (87.1\%), even if some underdeployments and insufficient coverage of the aneurysm neck needed additional therapeutic interventions. Aneurysm occlusion was evaluated using the Montreal scale. ${ }^{20}$ Since flow diversion treatment is associated with progressive thrombosis of the aneurysm, this classification is probably not entirely appropriate for aneurysms treated with FDs and alternative classifications have been proposed. ${ }^{21}$ As all aneurysms included in our series were previously treated with coils, the classification of Kamran et al was not really usable as the visibility of the intra-aneurysmal flow was partially hidden by the coil mesh.

At mid-term follow-up, complete occlusion was achieved in 17 of 28 aneurysms (60.7\%) and residual aneurysms were observed in five patients (17.9\%). These outcomes of aneurysm remnants are in agreement with published data on outcomes of de novo aneurysms. Piano et al obtained complete angiographic occlusion in $86 \%$ at 6 months, Berge et al observed complete occlusion in $84.5 \%$ at 1 year, and Becske et al obtained complete angiographic occlusion in $81.8 \% .^{1822} 23$ In their study of the treatment of recurrent IA with the Pipeline FD, Chalouhi et $a l^{19}$ obtained complete occlusion in $64.3 \%$.

In our study the treatment of recanalized aneurysms was associated with significant permanent morbidity (6.9\%) and there were no deaths related to the treatment. In the literature, the permanent morbidity rate is $6.7 \%$ for recurrent IA treated with the Pipeline FD, $1-5 \%$ for IA treated by flow diversion and $1.33 \%$ for residual aneurysms treated endovascularly or surgi-

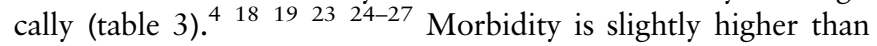
with standard coiling treatment for recanalized aneurysms but, because of the complex aneurysms included in our series (large and giant, wide-necked and multitreated), this safety profile is probably acceptable. Evaluation of systemic antiplatelet resistance was not systematically performed in the present series (only in one patient), which may explain the high rate of thromboembolic events. In our study, platelet function testing before the procedure may have identified the poor response of the patient with post-procedural MCA occlusion. The other patient had permanent morbidity due to hemorrhagic complications but he did not undergo testing. Such evaluation is certainly important because both thromboembolic and hemorrhagic complications may be due to a variable response to clopidogrel. Evaluation of the response to antiplatelet treatment could lead to modification of the perioperative medications or treatment strategy, contributing to a decrease in the rate of thromboembolic and hemorrhagic events. ${ }^{13} 2829$ However, no consensus is available about which tests to use and how to use the results.

Hemorrhagic complications were observed in two patients $(6.9 \%)$, with significant clinical worsening in one $(3.4 \%)$. In both cases, hemorrhage occurred early after treatment (1 day and 4 days after the procedure, respectively) and hematomas were remote from the treated aneurysm but on the ipsilateral side. Cruz et $a l^{30}$ analyzed four similar situations of delayed ipsilateral parenchymal hemorrhage and suggested that flow modification induced by the FD placement associated with antiaggregate therapy could be responsible for such complications. $\mathrm{Hu}$ et $a l^{31}$ performed three histopathological examinations of fatal delayed ipsilateral parenchymal hemorrhage and found foreign material around the hemorrhagic cavity. They suggested that hydrophilic material from the catheters could embolize and secondarily bleed. In the Pipeline for Uncoilable or Failed Aneurysms (PUFS) study and in a meta-analysis of FDs, hemorrhagic complications were reported in $1.9 \%$ and $3 \%$, respectively. ${ }^{18} 26$ No hemorrhagic complication occurred in patients with recanalized aneurysms treated with a standard approach in the study by Dorfer et al. ${ }^{4}$

We did not observe any delayed ruptures or cases of perianeurysmal brain edema in our series. ${ }^{32} 33$ In 2011 Berge et al ${ }^{34}$ reported a $41 \%$ incidence of perianeurysmal brain edema in aneurysms treated with flow diversion. In our series, as all the treated remnants were previously coiled some months before FD placement, the packing of these coils may contribute to reduce the intra-aneurysmal and perianeurysmal inflammatory reaction after flow diversion. It may also explain why no delayed rupture was observed in our series.

In our study, multitreated IA had a high recurrence rate needing several endovascular treatments. In this group, all aneurysms were initially treated with coils and subsequently with coils alone, stents or coils and stents. In this specific situation, continuing with the same modality of treatment (coiling or coiling and stenting) is not the logical treatment choice and the use of flow diversion is certainly highly recommendable when feasible. In this subgroup, flow diversion was associated with complete and appropriate occlusion in $5 / 7$ and $6 / 7$ patients, respectively.

\section{Limitations of the study}

Our series included a limited number of patients. However, most initial series of flow diversion have also included only a small number of patients. Owing to the retrospective nature of the analysis, our data remain subject to the biases of retrospective review. The anatomical results were evaluated by the treating physician which also introduced bias. Finally, the duration of follow-up was not uniform and was relatively short ( $<1$ year), but no recanalization was observed after complete occlusion in aneurysms treated with flow diversion and aneurysm occlusion was improved 6-12 months after the procedure. As a consequence, angiographic surveillance at 12 months in our study would show a higher occlusion rate. Further studies with longterm angiographic follow-up are needed to assess more precisely the long-term efficacy of this treatment.

Table 3 Comparison between our results and the literature on the mortality and permanent moribidity rates after FD placement

\begin{tabular}{llllllll}
\hline & Our series & PUFS & Kan et al & Saatci et al & Brinjikji et al & Piano et al & Leung et al \\
\hline Number of patients/aneurysms & $29 / 29$ & $108 / 11108$ & $56 / 58$ & $191 / 255$ & $1451 / 1654$ & $101 / 104$ & $414 / 448$ \\
Mortality (\%) & 3.40 & 3.0 & 7.1 & 0.5 & 4 & 3 & 1.50 \\
Permanent morbidity (\%) & 6.90 & 9.3 & 1.6 & 1.0 & 5 & 3 & 10.30 \\
\hline
\end{tabular}

FD, flow diverter; PUFS, Pipeline for Uncoilable or Failed Aneurysms. 


\section{CONCLUSION}

Flow diversion is a potential therapeutic alternative for the treatment of recanalized and multitreated aneurysms. The higher rate of permanent morbidity compared with standard coiling may be acceptable because of the complexity of the treated patients. Larger studies with long-term follow-up are needed to understand and decrease the rate of complications following the use of flow diversion for the treatment of recanalized and multitreated aneurysms.

Acknowledgements The authors thank Nagesh Uppuluri for his editorial assistance in the preparation of the manuscript.

Contributors All the authors drafted the manuscript, gave their final approval for publication and agreed to be accountable for all aspects of the work. AB and LP contributed to the conception of the work and to the acquisition, analysis and interpretation of data. A-CJ, DH, JB, MA, KK and CC contributed to the design of the work and to the acquisition of data.

\section{Competing interests None.}

Ethics approval Ethics approval was obtained from the Institutional Review Board of Reims University Hospital.

Provenance and peer review Not commissioned; externally peer reviewed.

\section{REFERENCES}

1 Molyneux A, Kerr R, Stratton I, et al. International Subarachnoid Aneurysm Trial (ISAT) Collaborative Group: International Subarachnoid Aneurysm Trial (ISAT) of neurosurgical clipping versus endovascular coiling in 2143 patients with ruptured intracranial aneurysms-a randomised trial. Lancet 2002;360:1262-3.

2 Pierot L, Cognard C, Ricolfi F, et al. on behalf of the CLARITY Investigators. Midterm anatomic results after endovascular treatment of ruptured intracranial aneurysms with GDC and Matrix coils: analysis of the CLARITY series. AJNR Am J Neuroradiol 2012;33:469-73.

3 Ferns SP, Sprengers MES, von Rooij WJ, et al. Coiling of intracranial aneurysms: a systematic review on initial occlusion and reopening and retreatment rates. Stroke 2009;40:523-9.

4 Dorfer $\mathrm{C}$, Gruber A, Standhardt $\mathrm{H}$, et al. Management of residual and recurrent aneurysms after initial endovascular treatment. Neurosurgery 2012;70:537-53.

5 The CARAT Investigators. Rates of delayed rebleeding from intracranial aneurysms are low after surgical and endovascular treatment. Stroke 2006;37:1437-42.

6 White PM, Lewis SC, Gholkar A, et al. HELPS trial collaborators. Hydrogel coated coils versus bare platinum coils for the endovascular treatment of intracranial aneurysms (HELPS): a randomised controlled trial. Lancet 2011;377:1655-62.

7 Pierot L, Cognard C, Anxionnat R, et al. for the CLARITY Investigators. Remodeling technique for endovascular treatment of ruptured intracranial aneurysms had a higher rate of adequate occlusion than did conventional coil embolization with comparable safety. Radiology 2011;258:546-53.

8 Piotin M, Blanc R, Spelle L, et al. Stent-assisted coiling of intracranial aneurysm: clinical and angiographic results in 216 consecutive aneurysms. Stroke 2010;41:110-15.

9 Campi A, Ramzi N, Molyneux AJ, et al. Retreatment of ruptured cerebral aneurysms in patients randomized by coiling or clipping in the International Subarachnoid Aneurysm Trial (ISAT). Stroke 2007:38:1538-44.

10 Molyneux AJ, Kerr RSC, Birks J, et al. for the ISAT Collaborators. Risk of recurrent subarachnoid haemorrhage, death, or dependence and standardised mortality ratios after clipping or coiling of an intracranial aneurysm in the International Subarachnoid Aneurysm Trial (ISAT): long-term follow-up. Lancet Neurol 2009;8:427-33.

11 Ries T, Siemonsen S, Thomalla G, et al. Long-term follow-up of cerebral aneurysms after endovascular therapy-prediction and outcome of retreatment. AJNR Am J Neuroradiol 2007:28:1755-61.

12 Ionita CN, Natarajan SK, Wang W, et al. Evaluation of a second-generation self-expanding variable-porosity flow diverter in a rabbit elastase aneurysm model. AJNR Am J Neuroradiol 2011;32:1399-407.
13 Fiorella D, Lylyk P, Szikora I, et al. The pipeline embolization device for the intracranial treatment of aneurysms trial. AJNR Am J Neuroradiol 2011; 32:34-40.

14 Walcott BP, Pisapia JM, Nahed BV, et al. Early experience with flow diverting endoluminal stents for the treatment of intracranial aneurysms. J Clin Neurosci 2011:18:891-4.

15 Wong GK, Kwan MC, Ng RY, et al. Flow diverters for treatment of intracranial aneurysms: current status and ongoing clinical trials. J Clin Neurosci 2011;18: 737-40.

16 Kallmes DF, Ding YH, Dai D, et al. A new endoluminal, flow-disrupting device for treatment of saccular aneurysms. Stroke 2007;38:2346-52.

17 Szikora I, Berentei Z, Kulcsar Z, et al. Treatment of intracranial aneurysms by functional reconstruction of the parent artery: the Budapest experience with the Pipeline embolization device. AJNR Am J Neuroradiol 2010;31:1139-47.

18 Becske T, Kallmes DF, Saatci I, et al. Pipeline for uncoilable or failed aneurysms: results from a multicenter clinical trial. Radiology 2013;267:858-68.

19 Chalouhi N, Chitale R, Starke RM, et al. Treatment of recurrent intracranial aneurysm with the Pipeline Embolization Device. J Neurointerv Surg 2014; 6:19-23.

20 Raymond J, Roy D. Safety and efficacy of endovascular treatment of acutely ruptured aneurysms. Neurosurgery 1997;41:1235-45.

21 Kamran M, Yarnold J, Grunwald IQ, et al. Assessment of angiographic outcomes after flow diversion treatment of intracranial aneurysms: a new grading schema. Neuroradiology 2011;53:501-8.

22 Berge J, Biondi A, Machi P, et al. Flow-diverter silk stent for the treatment of intracranial aneurysms: 1-year follow-up in a multicenter study. AJNR Am J Neuroradiol 2012;33:1150-5

23 Piano $\mathrm{M}$, Valvassori L, Quilici L, et al. Midterm and long-term follow-up of cerebral aneurysms treated with flow diverter devices: a single-center experience. J Neurosurg 2013;118:408-16.

24 Leung GKK, Tsang ACO, Lui WM. Pipeline embolization device for intracranial aneurysm: a systematic review. Clin Neuroradiol 2012;22:295-303.

25 Saatci I, Yavuz K, Ozer C, et al. Treatment of intracranial aneurysms using the pipeline flow-diverter embolization device: a single-center experience with long-term follow-up results. AJNR Am J Neuroradiol 2012;33:1436-46.

26 Kan P, Siddiqui AH, Veznedaroglu E, et al. Early postmarket results after treatment of intracranial aneurysms with the pipeline embolization device: a U.S. multicenter experience. Neurosurgery 2012;71:1080-7.

27 Brinjikji W, Murad MH, Lanzino G, et al. Endovascular treatment of Intracranial Aneurysms with flow-Diverters: a Meta-Analysis. Stroke 2013;44:442-7.

28 Delgado Almandoz JE, Crandall BM, Scholz JM, et al. Pre-procedure P2Y12 reaction units value predicts perioperative thromboembolic and hemorrhagic complications in patients with cerebral aneurysms treated with the Pipeline Embolization Device. J Neurointerv Surg 2013;5(Suppl 3):iii3-10.

29 Delgado Almandoz JE, Crandall BM, Scholz JM, et al. Last-recorded P2Y12 reaction units value is strongly associated with thromboembolic and hemorrhagic complications occurring up to 6 months after treatment in patients with cerebral aneurysms treated with the pipeline embolization device. AJNR Am I Neuroradiol Published Online First: 4 July 2013. doi:10.3174/ajnr.A3621

30 Cruz JP, Chow M, O'Kelly C, et al. Delayed ipsilateral parenchymal hemorrhage following flow diversion for the treatment of anterior circulation aneurysms. AJNR Am I Neuroradiol 2012;33:603-8.

31 Hu YC, Deshmukh VR, Albuquerque FC, et al. Histopathological assessment of fatal ipsilateral intraparenchymal hemorrhages after the treatment of supraclinoid aneurysms with the Pipeline Embolization Device. J Neurointerv Surg 2013. [Epub ahead of print].

32 Kulcsár Z, Szikora I. The ESMINT retrospective Analysis of delayed Aneurysm ruptures after flow diversion (RADAR) study (2012) EJMINT Original Article 1244000088.

33 Kulcsár Z, Houdart E, Bonafé A, et al. Aneurysmal thrombosis as a possible cause of delayed aneurysm rupture after flow-diversion treatment. AJNR Am J Neuroradiol 2011;32:20-5

34 Berge J, Tourdias $\mathrm{T}$, Moreau JF, et al. Peri-aneurysmal brain inflammation after flow diversion treatment. AJNR Am J Neuroradiol 2011:32:1930-4. 